\title{
Energy harvesting for active implants: powering a ruminal $\mathrm{pH}$-monitoring system
}

\begin{abstract}
Energy harvesting is a feasible method to prolong service life of implanted devices. We present a thermal energy harvesting approach for a ruminal $\mathrm{pH}$ monitoring probe in cattle. Thermoelectric generators utilize the temperature gradient between the probe and the ruminal fluid during water intake. The in vivo experiment yielded a maximum electric power of $32 \mu \mathrm{W}$.
\end{abstract}

Keywords: energy harvesting; in vivo; bovine ruminal $\mathrm{pH}$ monitoring

DOI: 10.1515/CDBME-2015-0005

\section{Introduction}

Most active implantable medical devices are powered by either primary or secondary batteries. Although these technologies are continuously advancing and both power density and capacity are improving, battery depletion entails loss of function or pre-emptive replacement surgery with all associated risks for the patient [1-4]. Energy harvesting is a feasible solution to render battery change unnecessary and to prolong service life of implanted devices [5-7]. It becomes even more interesting in cases where replacement surgery is impractical.

Continuously monitoring temperature and $\mathrm{pH}$ of the bovine ruminal fluid allows early detection of feed-related diseases $[8,9]$. Ruminal pH-monitoring systems are used in large livestock to improve feed efficiency as well as animal health, but most importantly to increase milk yield and quality in dairy cows [10]. For this purpose a $\mathrm{pH}$ measuring bolus is applied orally to the reticulorumen of each chosen indicator animal. The bolus can only be recovered after slaughter. Thus energy harvesting is desirable to ensure the coverage of the animal's entire productive life span.

The conditions in the reticulorumen of cattle offer a multitude of approaches to energy harvesting: Firstly, the reticulorumen of adult cattle, in which protozoa, bacte-

\footnotetext{
*Corresponding Author: T. Reuter: fzmb GmbH, Geranienweg 7, 99947 Bad Langensalza, Germany, E-mail: treuter@fzmb.de R. Machts, P.V. Prokop, O. Schewtschenko, M. Stubenrauch, C. Schilling, H. Witte: fzmb GmbH, Geranienweg 7, 99947 Bad Langensalza, Germany
}

ria, and fungi macerate the forage under anaerobic conditions, has a capacity of approximately $200 \ell$. The ruminal fluid contains considerable amounts of electrolytes and short-chain carboxylic acids at an average $\mathrm{pH}$ of 6.4 . Thus harvesting chemical energy using concentration gradients across a membrane is possible [11]. However, the huge amount of particles and microorganisms impair the membrane rapidly. Secondly, the reticuloruminal motility allows an intense mixing of the digesta, the eructation of the rumen gases, and the regulated further transport of the digesta into the omasum. In a healthy animal it varies from 0.5 contractions per minute in rest to eight contractions per minute during feeding $[12,13]$. So, kinetic energy can be harvested and electric power generated up to $8 \mu \mathrm{W}$ [14]. Thirdly, the core body temperature of a healthy cow is $39^{\circ} \mathrm{C}$. Dairy cattle take in up to $150 \ell$ of water per day usually with 5 to $8 \ell / \mathrm{min}$, maximally $25 \ell / \min [15,16]$. In this study temperature gradients in the reticulorumen caused by trough water are utilized to harvest energy using the Seebeck effect.

\section{Methods}

A prerequisite for this method of energy harvesting is trough water colder than the core temperature of the animal. In the reticulum a much higher temperature gradient may be observed than in the rumen due to the reticulum's smaller size and its situation between oesophagus and rumen. Placing temperature sensors in reticulum and rumen of a cannulated cow for six days a maximum temperature drop of $5 \mathrm{~K}$ and $1.5 \mathrm{~K}$, respectively, was observed while drinking water of $10^{\circ} \mathrm{C}$.

The ruminal bolus, shown schematically in Figure 1, is a polyoxymethylene (POM) cylinder of $170 \mathrm{~mm}$ length and a diameter of $30 \mathrm{~mm}$ both ends covered with POM caps of $2 \mathrm{~mm}$ thickness. Into this housing was implemented a stack of three thermopiles TEC1-3104 in series circuit. A copper plate $(22 \mathrm{~mm} \times 22 \mathrm{~mm} \times 5 \mathrm{~mm})$ served as a thermal bridge between one cap and the thermopiles. Additionally a weight was integrated into the bolus to increase density above $1.5 \mathrm{~g} / \mathrm{cm}^{3}$ ensuring retention in the reticuloru- 
men. As a positive side-effect the heat capacity increased as well.

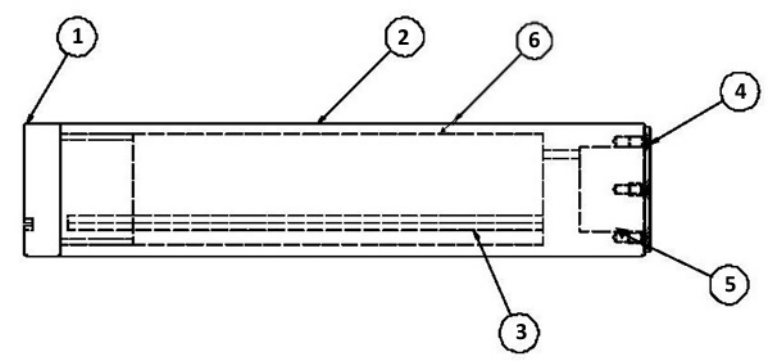

Figure 1: Design of the ruminal bolus (1 cap, 2 POM body, 3 weight, 4 cap and copper plate, 5 thermopile, 6 room for data logger).

The heat differential between the cooled ruminal fluid and the ruminal bolus, which has the body core temperature of $39^{\circ} \mathrm{C}$, generates a direct current in the integrated thermopiles.

The reticulum with its better thermal conditions was inaccessible for this experiment. The bolus was placed in the rumen of a cannulated cow for 221 hours. Bolus temperature and voltage of the thermoelectric generators were recorded with a Track-It ${ }^{\circledR}$ data logger (Monarch Instrument, Amherst, $\mathrm{NH}$ ) at a sample rate of 30 seconds. The trough water temperature and flow rate during drinking were recorded using a mikromec ${ }^{\circledR}$ multisense (Technetics, Freiburg i. Br.) data logger.

The in vivo experiment was carried out according to German animal protection legislation (Reg. No. 14-004/11). The animal was a Holstein Frisian being dry and feeding on hay ad libitum.

\section{Results}

The trough water temperature was $10^{\circ} \mathrm{C}$. The water intake per day varied between 40 and $60 \ell$. Trough water flow rate, ruminal temperature profile, and generated thermoelectric voltage measured during the entire experiment are depicted in Figure 2. It is evident, that each water flow coincided both with a decrease of ruminal temperature and an increase of voltage.

The average ruminal temperature during this in vivo study was $39.2^{\circ} \mathrm{C}$, as expected in healthy cattle. Temperature differences of up to $2.25 \mathrm{~K}$ were detected during the 13250 minutes (221 hours) of the experiment. The maximum open circuit voltage of $25 \mathrm{mV}$ was recorded at minute 8488. Peak voltages occurred approximately five minutes after water intake.
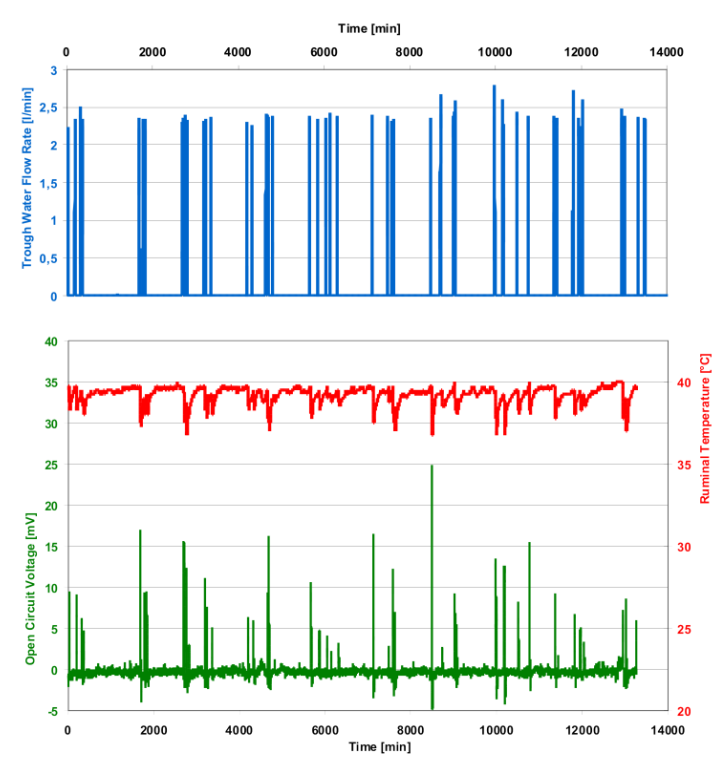

Figure 2: Trough water flow rate, ruminal temperature, and generated open circuit voltage during the entire experiment.

Considering the generated voltage, the amount of water taken in appears to be of small importance. For instance at minute 8488 a voltage of $25 \mathrm{mV}$ was generated by a water intake of $c a .16 \ell$, while an intake of $14 \ell$ caused a voltage of $9 \mathrm{mV}$ at minute 13006. This suggests that other parameters may be of greater importance, e. g. the position of the bolus within the reticulorumen.

Electrical power was generated periodically for approximately ten minutes after each drinking event. Thus the generated continuous power was low. For example the electric power generated on day 2 is shown in Figure 3. This day five power peaks occurred, the highest with $32 \mu \mathrm{W}$ at $250 \mathrm{~min}$. The day's average of generated power amounted to $0.31 \mu \mathrm{W}$.

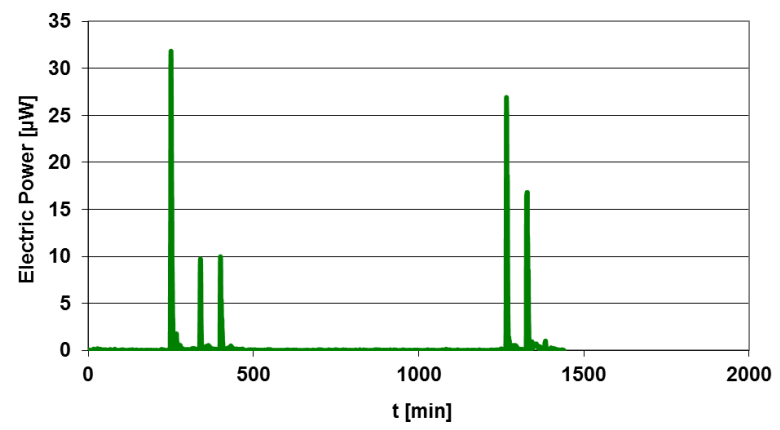

Figure 3: Electric power generated in the reticulorumen at day 2 of the experiment. 
Furthermore, the energy generated per day (Table 1) was calculated from the generated electric power. The energy generated per day averaged to $14.4 \mathrm{~mJ}$. The generated energy peaked at day 2 with $26.7 \mathrm{~mJ}$.

Table 1: Energy harvested in the reticulorumen per day.

\begin{tabular}{ll}
\hline Day & Harvested energy per day $[\mathrm{mJ}]$ \\
\hline 1 & 8.1 \\
2 & 26.7 \\
3 & 7.9 \\
4 & 14.9 \\
5 & 10.5 \\
6 & 23.5 \\
7 & 12.4 \\
8 & 18.3 \\
9 & 7.6 \\
\hline
\end{tabular}

\section{Conclusion}

This study aimed at the development of a persistent energy harvesting power supply for a ruminal $\mathrm{pH}$-monitoring system in cattle. The thermal gradients, which inevitably occur in the reticulorumen during water intake, were utilized to generate electric energy. However, some effort in optimising the performance yield is still needed to supply a micropower boost voltage converter sufficiently. More effective thermopiles should be used and the thermal capacity of the bolus increased. A drastic increase of generated power is expected from putting the bolus directly into the reticulum and exploiting its higher heat differential. Thus, the feasibility of thermal energy harvesting in the reticulorumen of cattle is proven, but also the necessity of further research.

Acknowledgement: This project was funded by the German Federal Ministry of Education and Research (Reg. No. 03WKCB01D). The authors would like to thank the Veterinary Clinic of the fzmb $\mathrm{GmbH}$ for supporting the in vivo experiment.

\section{Author's Statement}

Conflict of interest: Authors state no conflict of interest. Material and Methods: Informed consent: Informed consent has been obtained from all individuals included in this study. Ethical approval: The research related to human use has been complied with all the relevant national regulations, institutional policies and in accordance the tenets of the Helsinki Declaration, and has been approved by the author's institutional review board or equivalent committee.

\section{References}

[1] Siontis KC, Pantos I, Katritsis DG. Comparison of the longevity of implantable cardioverter-defibrillator devices by different manufacturers. Int. J. Cardiol. 2014, 175 (2): 380 - 382

[2] Gadler F, Valzania C, Linde C. Current use of implantable electrical devices in Sweden: data from the Swedish pacemaker and implantable cardioverter-defibrillator registry. Europace 2014, 17 (1): 69 - 77

[3] Bolash R, Udeh B, Saweris Y, Guirquis M, Dalton JE, Makarova N, Mekhail N. Longevity and Cost of Implantable Intrathecal Drug Delivery Systems for Chronic Pain Management: A Retrospective Analysis of 365 Patients. Neuromodulation 2014, Sep 23, DOI: 10.1111/ner.12235 [Epub ahead of print]

[4] Steward CDM, Eljamel S. Prediction of Implantable Pulse Generator Longevity. In: Deep Brain Stimulation: Limitations and Possible Solutions in Clinical Practice. Stereotact. Funct. Neurosurg. 2011, 89 (5): $299-304$

[5] Dembowski K. Energy Harvesting für die Mikroelektronik. Berlin, Offenbach: VDE-Verlag GmbH 2011

[6] Pfeffinger A, Jonsson M, Zurbuchen A, Koch VM, Vogel R. Energy harvesting from the cardiovascular system, or how to get a little help from yourself. Ann. Biomed. Eng. 2013, 41 (11): $2248-2263$

[7] Pfeffinger A, Vogel R, Koch VM, Jonsson M. Performance analysis of a miniature turbine generator for intracorporeal energy harvesting. Artif. Organs 2014, 38 (5): E68 - 81

[8] Gasteiner J, Guggenberger T, Häusler J, Steinwidder A. Continuous and Long-Term Measurement of Reticuloruminal $\mathrm{pH}$ in Grazing Dairy Cows by an Indwelling and Wireless Data Transmitting Unit. Vet. Med. Int. 2012, Article ID 236956

[9] Kaden H, Zosel J. pH-Messung in der Tierphysiologie, besonders im Pansen von Milchkühen. Tech. Mess. 2013, 80 (7 - 8): $236-242$

[10] Gasteiner J, Horn M, Steinwidder A. Continuous measurement of reticuloruminal $\mathrm{pH}$ values dairy cows during the transition period from barn to pasture feeding using an indwelling wireless data transmitting unit. J. Anim. Physiol. Anim. Nutr. 2014, Sep 30, DOI: 10.1111/jpn.12249 [Epub ahead of print]

[11] Golemme G. Perfluoropolymer Membranes for Separations and Electrochemical Processes. In: Advanced Materials for Membrane Preparation. Buonomenna MG, Golemme G., editors. Bentham Books 2012, ISBN 978-1-60805-505-0 [ebook]

[12] v. Engelhardt W, Breves G. Physiologie der Haustiere. Stuttgart: Enke-Verlag 2000

[13] Hoffmann RR, Schnorr B. Die funktionelle Morphologie des Wiederkäuermagens. Stuttgart: Enke-Verlag, 1982

[14] Reuter T, Beck M, Liebold S, Hoffmann M, Hörschelmann P, Weisheit E, Schmidt S, Bartsch T. Entwicklung eines Generators zur Energieversorgung von Biosensoren. 11. Dresdner Sensor-Symposium 2013, Tagungsband: S.138-142. DOI: 10.5162/11dss2013/A2 
[15] Flachowsky G, Lebzien P, Meyer U. Steigende Milchleistungen: kann die Tierernährung Schritt halten? Landbauforsch. Völkenrode SH 2002, 242: $43-52$
[16] Beede DK. Water for dairy cattle. In: Large Dairy Herd Management. van Horn HH, Wilcox CJ, Champaign (IL): Am. Dairy Sci. Assoc. 1992: $260-268$ 